\title{
PROPOSIÇÕES ERGONÔMICAS PARA O CENTRO DE CONVIVÊNCIA ALBERT SABIN - UMA APLICAÇÃO DA METODOLOGIA ERGONOMICA DO AMBIENTE CONSTRUIDO - MEAC
}

\section{ERGONOMIC PROPOSITIONS FOR THE ALBERT SABIN COEXISTENCE CENTER - AN APPLICATION OF THE ERGONOMICS METHODOLOGY OF THE BUILT ENVIRONMENT - MEAC}

(1) NASCIMENTO, Juliana Pessoa do ${ }^{1}$

(2) MACIEL, Ana Maria Moreira²

(1) UNINASSAU - graduada em Arquitetura e Urbanismo e-mail: juliana.p.nascimento@hotmail.com

(2) UFPE - Msc. em Gestão Pública e-mail: anamariamaciel@yahoo.com.br

Palavras-chave em português (Avaliação Ergonômica para Ambientes Construídos; Acessibilidade, Centro de Convivência Albert Sabin)

Projetar espaços mais abrangentes e menos restritivos é uma tendência mundial que vem se propagando na busca pela melhoria da qualidade de vida. Este estudo objetiva analisar o espaço construído sobre a ótica dos deficientes físicos através da Metodologia de Avaliação Ergonômica para Ambientes Construídos - MEAC. Serão avaliados aspectos da Ergonomia aplicados ao Centro de Convivência Albert Sabin, Paulista, Pernambuco.

Key-words in English (Ergonomic Assessment for Constructed Environments; Accessibility, Albert Sabin Community Center.)

Designing spaces that are more comprehensive and less restrictive is a worldwide trend that has been spreading with the other parameters that confer quality of life. This study aims to analyze the space built on the physics of the disabled through the Methodology of Ergonomic Assessment for Built Environments - MEAC (Metodologia de Avaliação Ergonômica para Ambientes Construídos). Ergonomics aspects will be evaluated by analyzing the users of the Albert Sabin Center, Paulista, Pernambuco. 


\section{$16^{\circ}$ \\ ERGODESIGN \\ USIHC CINAHPA}

\section{Introdução}

O estatuto da pessoa com deficiência foi instituído pela Lei Brasileira $\mathrm{N}^{\circ} 13.146 / 2015$, e tem por finalidade assegurar e promover igualdade, direitos entre outras garantias previstas por lei. Sabe-se, no entanto que, assegurar o que institui na lei é um desafio a se vencer no Brasil.

As cidades não proporcionam autonomia para seus habitantes, sejam eles portadores ou não de alguma incapacidade física, embora seja uma tendência mundial na busca pela qualidade de vida.

Atualmente os projetos e estudos arquitetônicos sobrevêm de uma pobre abordagem ergonômica. Esta lacuna encontra-se ausente no processo de formação de muitos arquitetos que seguem na elaboração de projetos ineficazes, onde a percepção entre o usuário e o ambiente construído é praticamente nula. (VASCONCELOS; SOARES; MARTINS, 2010).

Portanto, faz-se necessário um aprofundamento nos métodos e estudos ergonômicos para melhor compreensão das limitações e habilidades dos indivíduos de modo que o objetivo do arquiteto vá além dos ambientes eficazes, mas que atendam as reais necessidades funcionais dos usuários na realização das suas atividades.

O presente estudo trata-se de uma pesquisa exploratório-descritiva, que tem como objetivo relatar a complexidade da relação entre deficientes físicos e os espaços construídos sobre o aspecto da acessibilidade, através de descrições, observações, levantamento de dados, entrevistas e questionários com a finalidade de aprofundar-se no conhecimento sobre as características, valores e $16^{\circ}$ Ergodesign - Congresso Internacional de Ergonomia e Usabilidade de Interfaces Humano Tecnológica: Produto, Informações Ambientes Construídos e Transporte

$16^{\circ}$ USIHC - Congresso Internacional de Ergonomia e Usabilidade de Interfaces Humano Computador

CINAHPA | 2017 - Congresso Internacional de Ambientes Hipermídia para Aprendizagem. problemas enfrentados pelos usuários numa perspectiva inclusiva.

Baseando-se na Metodologia de Análise Ergonômica para Ambientes Construídos - MEAC, serão avaliados os aspectos referentes ao conforto ambiental, percepção ambiental, adequação de materiais, acessibilidade e medidas antropométricas, tendo como foco os usuários do Centro de Convivência Albert Sabin que localizase no bairro de Arthur Lundgren I na cidade do Paulista - Pernambuco.

\section{Centro de Convivência Albert Sabin}

O Centro de Convivência Albert Sabin, foi inaugurado em 1993 tendo como objetivo proporcionar moradia, espaços de trabalho e atividades esportivas voltadas para pessoas com deficiência física. Tendo como idealizadora da proposta a socióloga e também deficiente física, Jurene Pereira (1950).

Na época, o então governador Joaquim Francisco (1948) aprovou a elaboração do projeto do Centro de Convivência, que posteriormente foi implantado no terreno onde se situava a garagem da antiga Companhia de Habitação Popular do Estado de Pernambuco - COHAB/PE.

O projeto disponibilizava vinte e quatro casas do tipo geminadas, uma quadra poliesportiva e uma edificação onde funcionavam oficinas de trabalho, uma proposta inovadora desde a sua concepção.

Sabendo que qualquer espaço, seja ele edificado ou não, está sujeito a modificações incessantes, e após décadas desde sua instalação, o Centro de Convivência Albert Sabin atualmente não pode ser considerado como acessível uma vez que há 


\section{$16^{\circ}$ \\ ERGODESIGN USIHC CINAHPA}

inúmeros fatores internos e externos que

modificaram suas condições de uso inicial.

A partir da identificação de variáveis que interferem no adequado uso dos espaços tido como acessíveis, o estudo propõe avaliar o ambiente externo sobe a ótica dos habitantes deste espaço, identificando como ocorrem as relações usuáriosambiente e que ações são necessárias para promover a acessibilidade plena.

\section{Metodologia}

Esta pesquisa classifica-se como qualitativa, haja vista que este tipo de investigação busca o contato direto entre o pesquisador e a situação que está sendo investigada por meio do trabalho de campo.

A técnica de análise da pesquisa baseia-se na premissa sistêmica da Metodologia Ergonômica de Avaliação para Ambientes Construídos - MEAC, que analisa o espaço físico conjugando avaliações físico-espaciais e ferramentas de identificação da percepção ambiental (VILLAROUCO, 2008).

\subsection{Análises Física do Centro de Convivência Albert Sabin}

\subsubsection{Análise global do ambiente}

O Centro de Vivência Albert Sabin está situado na Zona de Média Densidade 2-ZMD2, e integra a zona urbana que compreende as áreas dos grandes conjuntos habitacionais, segundo o Plano Diretor da Cidade do Paulista.

As ocupações habitacionais vizinhas ao Centro de Convivência Albert Sabin, são predominantemente residências de interesse social.

O entorno do Centro de Convivência é marcado pela diversidade de usos fazendo divisa com a $16^{\circ}$ Ergodesign - Congresso Internacional de Ergonomia e Usabilidade de Interfaces Humano Tecnológica: Produto, Informações Ambientes Construídos e Transporte

$16^{\circ}$ USIHC - Congresso Internacional de Ergonomia e Usabilidade de Interfaces Humano Computador

CINAHPA | 2017 - Congresso Internacional de Ambientes Hipermídia para Aprendizagem.

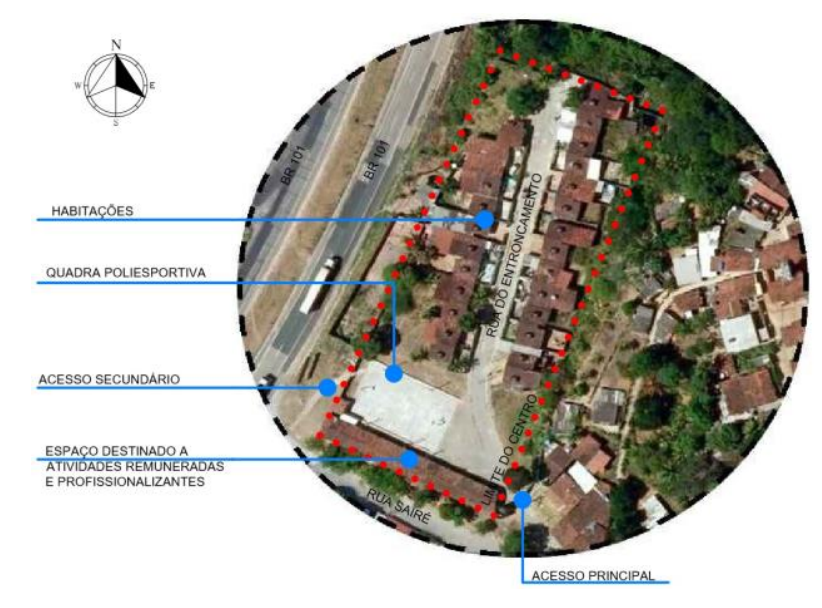

Figura 01: Situação do Centro de Convivência Albert Sabin. Fonte: Google mapas, adaptado pelos autores (2016).

\subsubsection{Identificação da configuração ambiental}

O ambiente avaliado foi à área de uso comum do centro de Convivência Albert Sabin, cujo lote dispõe de aproximadamente $10.100,84 \mathrm{~m}^{2}$. Inicialmente o projeto viabilizou a construção das residências, de uma guarita de segurança, da associação desportiva, uma quadra poliesportiva e um alojamento para os atletas que não residiam no Centro.

No decorrer dos anos o Centro de Convivência sofreu alterações com relação a sua estrutura física, tendo por finalidade à readequação as necessidades dos indivíduos que residem no local.

Foram adicionados muros em volta das edificações assim como a criação do acesso secundário nas margens da BR 101. A guarita de segurança foi desativada e parte dos proprietários ampliaram as residências durante esse período. 


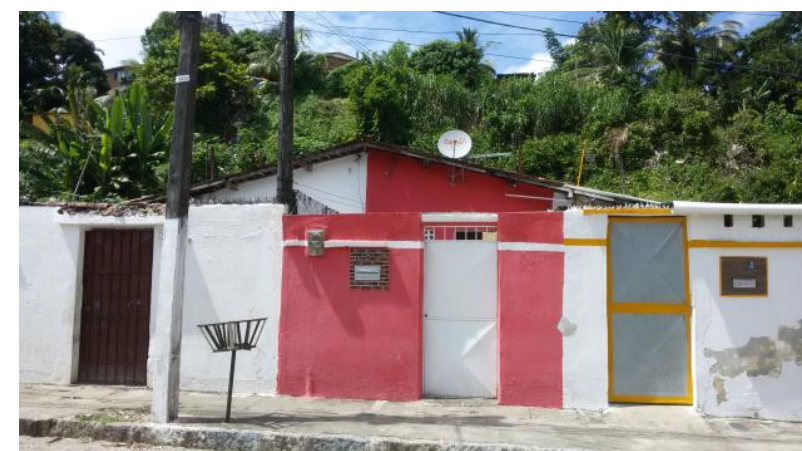

Figura 02: Situação das edificações atualmente. Fonte: Os autores (2016).

Os acessos possuem uma inclinação maior do que a indicada nas normas, dificultando a circulação das pessoas com baixa mobilidade ou que necessitam da cadeira de rodas para locomover-se.

Com relação ao conforto térmico o que observou foi que as residências e a quadra esportiva localizada a Noroeste recebe sol durante todo o dia tornando os ambientes quentes e desconfortáveis.

Em relação ao conforto luminico os resultados obtidos estão abaixo dos índices indicados pela norma (NBR 5101/2012), na área residencial a média obtida está entre 25 lux e 30 lux, quando deveria ser no mínimo de 50 lux. A iluminação geral do Centro no período noturno é precária e na quadra esportiva a ausência de lâmpada em um dos refletores compromete a eficiência.

A proximidade com a BR 101 é a responsável pela avaliação negativa do conforto acústico e da poluição sonora.

\subsubsection{Avaliação do ambiente em uso}

Esta etapa da pesquisa consiste na observação dos aspectos relacionados ao ambiente em uso, identificando o quanto o mesmo funciona como elemento facilitador ou dificultador quanto ao desenvolvimento das atividades que abriga (MONT'ALVÃO e VILLAROUCO, 2014). $16^{\circ}$ Ergodesign - Congresso Internacional de Ergonomia e Usabilidade de Interfaces Humano Tecnológica: Produto, Informações Ambientes Construídos e Transporte

$16^{\circ}$ USIHC - Congresso Internacional de Ergonomia e Usabilidade de Interfaces Humano Computador

CINAHPA | 2017 - Congresso Internacional de Ambientes Hipermídia para Aprendizagem.

As principais atividades desenvolvidas nas áreas comuns do Centro de Convivência Albert Sabin são: Limpeza das calçadas e linha d'água, atividades esportivas na quadra poliesportiva e recreação por parte das crianças que residem no Centro ou moram no entorno imediato.

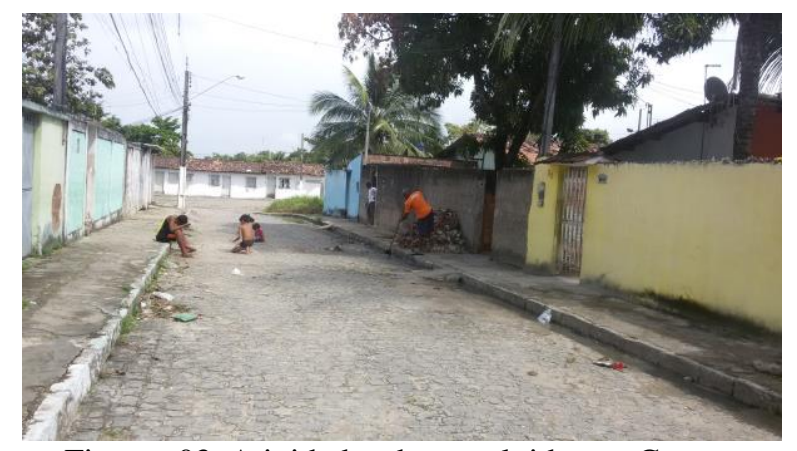

Figuras 03: Atividades desenvolvidas no Centro. Fonte: Os autores (2016).

Vale destacar a situação encontrada nas calçadas de acesso as residências, além da irregularidade do piso, pode-se observar obstáculos por todo o percurso da mesma, apresentando dimensões inferiores ao recomendado pela NBR 9050/2015, tornando inacessível aos usuários do Centro.

As atividades na quadra poliesportiva ocorrem semanalmente por moradores da vizinhança, os paratletas não se beneficiam desse espaço devido ao desconforto térmico ocasionado pela ausência de uma cobertura nas dependências da quadra e a incompatibilidade do piso para atividades esportivas em cadeira de rodas.

A ausência de um estacionamento seja para visitantes ou moradores é um dos fatores que dificultam o uso da quadra poliesportiva, uma vez que na falta de espaço apropriado, os motoristas estacionam os veículos nas dependências da quadra, impossibilitando o uso da mesma e podendo causar danos ao piso. 


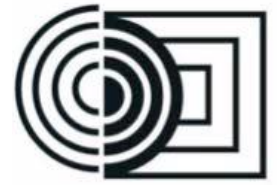

\section{$16^{\circ}$}

ERGODESIGN

USIHC CINAHPA

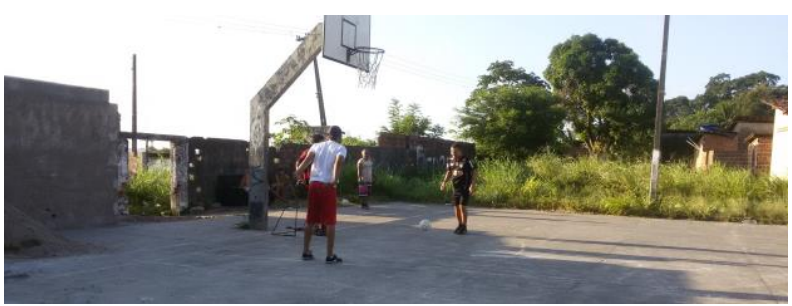

Figuras 04: Uso da quadra poliesportiva no Centro. Fonte: Os autores (2016).

$\mathrm{Na}$ entrada principal o tipo de abertura e o material do portão são inadequados para os proprietários do Centro, uma vez que os impossibilita de empurrar ou descer do veículo para abrir o mesmo. A área onde existiu uma guarita de segurança, hoje é um ponto para acúmulo de lixo e entulhos.

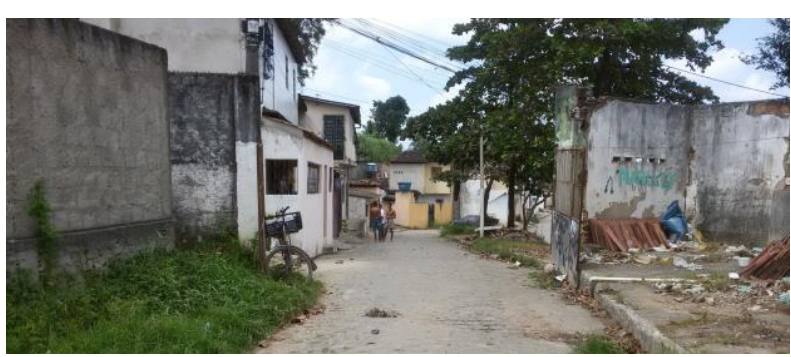

Figuras 05: Entrada principal do Centro.

Fonte: Os autores (2016).

As ruas não são pavimentadas e a presença de buracos, lixo e esgoto a céu aberto comprometem a utilização desses espaços.

\subsubsection{Percepção Ambiental}

Esta etapa da pesquisa tem por finalidade a compreensão e a percepção espacial dos usuários do Centro de Convivência Albert Sabin. Nesta fase foram selecionados dez moradores, devido à diversidade de usuários com necessidades distintas.

As informações captadas nas entrevistas contribuíram para o entendimento do ambiente construído, sabendo que a deficiência do local avaliado pode variar de acordo com o perfil dos entrevistados. $16^{\circ}$ Ergodesign - Congresso Internacional de Ergonomia e Usabilidade de Interfaces Humano Tecnológica: Produto, Informações Ambientes Construídos e Transporte

$16^{\circ}$ USIHC - Congresso Internacional de Ergonomia e Usabilidade de Interfaces Humano Computador

CINAHPA | 2017 - Congresso Internacional de Ambientes Hipermídia para Aprendizagem.

Para a segunda fase foram realizadas entrevistas através da ferramenta Constelação de Atributos, seguindo as recomendações de Villarouco (2008). Esta fase foi dividida em duas etapas, a primeira referente às características espontâneas dos usuários do Centro de Convivência Albert Sabin e a segunda refere-se às características induzidas.

A análise da imagem simbólica do ambiente ideal na percepção dos moradores do Centro de Convivência Albert Sabin, foi promovida com a seguinte pergunta: “Quando você pensa em um ambiente que te proporciona moradia, espaços de lazer e trabalho, o que vem à mente? ”

Após a identificação e enumeração dos atributos ligados ao ambiente ideal, foi promovida a pergunta referente ao ambiente real através da pergunta: "Quando você pensa no Centro de Convivência Albert Sabin que proporciona moradia, espaços de lazer e trabalho, o que vem à mente?"

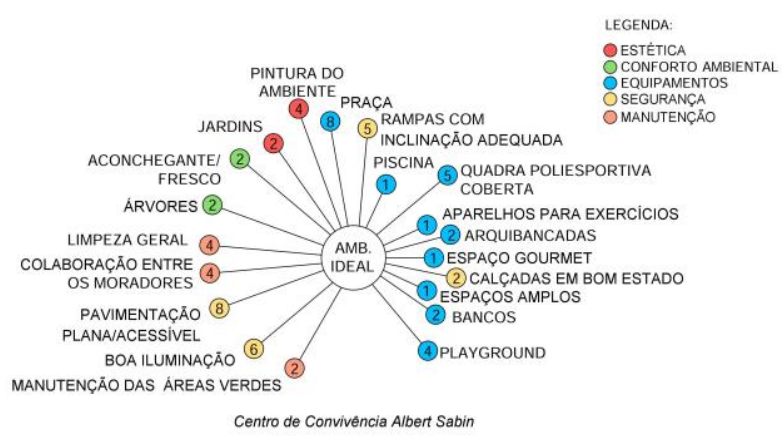

Figura 06: Constelação de atributos - Ambiente ideal. Fonte: Os autores.

Da análise das Constelações de Atributos do Ambiente Real e Imaginário se destacam nas respostas a prevalência das questões relativas a categorias equipamentos e segurança.

A implantação de uma praça, de playground e cobertura na quadra poliesportiva se sobressai nos equipamentos desejados. 
$16^{\circ}$ Ergodesign - Congresso Internacional de Ergonomia e Usabilidade de Interfaces Humano Tecnológica: Produto, Informações Ambientes Construídos e Transporte

$16^{\circ}$ USIHC - Congresso Internacional de Ergonomia e Usabilidade de Interfaces Humano Computador

CINAHPA | 2017 - Congresso Internacional de Ambientes Hipermídia para Aprendizagem.

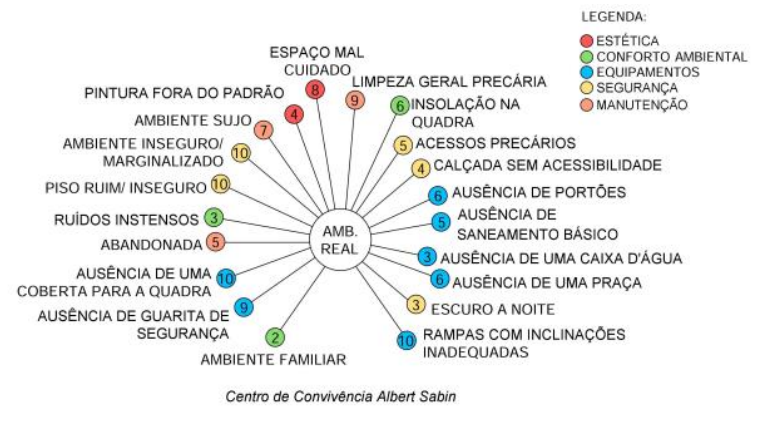

Figura 07: Constelação de atributos - Ambiente real. Fonte: Os autores.

\subsubsection{Diagnóstico ergonômico do ambiente e recomendações}

Nesta etapa são compiladas todas as informações necessárias para o entendimento geral da situação, ou seja, todos os elementos coletados das etapas anteriores apresentados e confrontados, desde os problemas até os pontos positivos encontrados. Desta maneira, torna-se possível propor recomendações de melhoria e soluções para os problemas do objeto analisado (VILLAROUCO, 2011).

\section{Proposições Ergonômicas}

Diante da demanda ergonômica obtida através da análise do Centro de Convivência Albert Sabin, estão listadas abaixo algumas das recomendações feitas para adequação da área externa e das atividades estudadas durante a pesquisa.

- Realização do tratamento acústico para a área analisada utilizando vegetações como barreira acústica adequando o ambiente de acordo com a NBR 10151/2000.

- Ocupar as áreas em desuso com espaços que proporcionem lazer e interação entre os habitantes do Centro, com a elaboração de uma horta comunitária, e uma praça com área para playground.

- Reformar a quadra poliesportiva propondo um novo revestimento para o piso e uma estrutura para cobertura da mesma, viabilizando a conservação e a realização dos eventos esportivos no Centro.
- Reconstrução da guarita de segurança a fim de proporcionar aos moradores do Centro um espaço com a finalidade de preservar o controle dos acessos.

- Fechamento dos acessos por meio de portões com a finalidade de proporcionar o controle dos mesmos a área interna do Centro de Convivência.

- Rever e adequar o dimensionamento dos acessos, rampas e calçadas utilizando a NBR 9050/2015.

\section{CONCLUSÃO}

Sendo este trabalho, parte de uma pesquisa mais abrangente que visa identificar as condições de habitabilidade e acessibilidade a pessoas com deficiência, objetivando gerar recomendações ergonômicas a esse tipo de projeto, coloca-se nele significativa contribuição à pesquisa devido ao processo de ocupação e a diversidade de usuários portadores de deficiências em um mesmo espaço, podendo colaborar para a melhor consecução futura das demais análises.

\section{BIBLIOGRAFIA}

MONT'ALVÃO, Claudia; VILLAROUCO, Vilma. Um novo olhar para o projeto 2: a ergonomia no ambiente construído. UFPE, p.247. Recife 2014.

VASCONCELOS, Cristiane F; VILLAROUCO, Vilma; SOARES, Marcelo M. Contribuição da psicologia ambiental na análise ergonômica do ambiente construído. Ação Ergonômica, Vol. 5, num 3, p. 14-20, 2010.

VILLAROUCO, Vilma; ANDRETO, Luiz F. M. Avaliando desempenho de espaços de trabalho sob o enfoque da ergonomia do ambiente construído. Produção, vol. 18, num. 3, p. 523-539, 2008. 